\title{
A defectologia e o estudo do desenvolvimento e da educação da criança anormal
}

Lev Semionovitch Vigotski

Este artigo, inédito no Brasil, foi traduzido diretamente do russo por Denise Regina Sales, Marta Kohl de Oliveira e Priscila Nascimento Marques, que constituem um grupo de tradução dedicado às obras de Vigotski. 0 texto original (VIGOTSKI, L. S. Defektologuia i utchenie o razvitii i vospitanii nenormálnogo rebionka. In: Problemi defektologuii [Problemas de defectologia]. Moscou: Prosveschenie, 1995. p. 451-458.) tem sua data de produção desconhecida, mas provavelmente foi escrito entre 1924 e 1931. Sua primeira publicação data de 1983, no quinto volume das Obras escolhidas, em russo (VIGOTSKI, L. S. Obras escolhidas. t. 5. Moscou: Pedagoguika, 1983. p. 166-173); posteriormente, o texto foi publicado nas traduções feitas na Espanha (1997) e nos Estados Unidos (1993). Os termos defectologia e criança anormal, utilizados no título e ao longo do artigo, foram mantidos na presente tradução por corresponderem à terminologia utilizada no início do século XX, quando Vigotski produziu seus textos. Atualmente, seriam equivalentes às expressões deficiência e educação especial e criança com deficiência, respectivamente. Além do interesse histórico e da indiscutivel relevância de fazer traduções diretas da obra vigotskiana, destaca-se neste artigo a postulação do desenvolvimento como um percurso tortuoso, atravessado por rupturas e conflitos, e a tese central do autor de que caminhos indiretos de desenvolvimento são possibilitados pela cultura quando o caminho direto está impedido. Isso teria especial importância no caso das crianças com deficiência. 0 desenvolvimento cultural seria, assim, a principal esfera em que é possível compensar a deficiência. 
Atualmente, a questão consiste em romper o aprisionamento biológico da psicologia e passar para o campo da psicologia histórica, humana. A palavra social, aplicada à nossa disciplina, possui um importante significado. Antes de mais nada, em seu sentido mais amplo, essa palavra indica que tudo o que é cultural é social. A cultura também é produto da vida em sociedade e da atividade social do homem e, por isso, a própria colocação do problema do desenvolvimento cultural já nos introduz diretamente no plano social do desenvolvimento. Além disso, seria possível apontar para o fato de que o signo localizado fora do organismo, assim como o instrumento, está separado do indivíduo e consiste, em essência, num órgão da sociedade ou num meio social. Ademais, poderíamos dizer que todas as funções superiores formaram-se não na biologia nem na história da filogênese pura - esse mecanismo, que se encontra na base das funções psíquicas superiores, tem sua matriz no social. Poderíamos indicar o resultado fundamental a que nos conduz a história do desenvolvimento cultural da criança como a sociogênese das formas superiores de comportamento.

A estrutura das formas complexas de comportamento da criança consiste numa estrutura de caminhos indiretos, pois auxilia quando a operação psicológica da criança revela-se impossível pelo caminho direto. Porém, uma vez que esses caminhos indiretos são adquiridos pela humanidade no desenvolvimento cultural, histórico, e uma vez que o meio social, desde o início, oferece à criança uma série de caminhos indiretos, então, muito frequentemente, não percebemos que o desenvolvimento acontece por esse caminho indireto.

Um exemplo simples. Vamos imaginar que precisamos escolher em qual de dois grupos há mais objetos, ou, então, que precisamos dividir determinado grupo de objetos em certo número de partes (dividir brinquedos ou peças entre algumas pessoas presentes). A operação mais simples seria a seguinte: dividir os objetos a olho, como fazem as crianças mais novas ou o homem primitivo ${ }^{1}$. Nós, homens culturais, e as crianças de idade escolar mais avançada, para fazer a divisão, usamos o caminho indireto; primeiramente, contamos os objetos e, dessa forma, o objetivo fundamental de dividir fica em segundo plano. Os homens culturais contam primeiro os objetos, depois os participantes presentes; em seguida, efetuam a operação aritmética, por exemplo, dividem 64 objetos entre quatro participantes. 0 número obtido indica quantos objetos devem ficar com cada um. Apenas depois disso a divisão tem início. Em outras palavras, o objetivo fundamental, sem dúvida, não é alcançado de modo direto, assim que surge a tarefa. Mesmo em crianças de tenra idade, ele é adiado, é deixado para o final, e o intervalo é preenchido por uma série de operações, que consistem em um caminho indireto para a resolução da tarefa.

Do mesmo modo, a criança começa a contar nos dedos quando, por não estar em condições de dar uma resposta direta à pergunta do professor sobre o resultado de 6 mais 2, ela conta nos dedos 6, depois 2 e diz: 8 . Aqui temos novamente a estrutura do caminho indireto para a realização de determinada operação - uma conta: a criança, sem ter uma resposta pronta, automática, utiliza as próprias mãos, que antes eram para ela somente pano de fundo. Nesse caso, as mãos, que não possuem relação direta com a pergunta, adquirem significado de instrumento assim que a execução da tarefa pelo caminho direto se mostra impedida para a criança. Com base nessas colocações, poderíamos determinar também as próprias funções, o próprio propósito que cumpre essa operação cultural na vida da criança. A estrutura do caminho indireto surge apenas quando aparece um obstáculo ao caminho direto, quando a

1 - Fortemente influenciado por Lucien Lévy-Bruhl, Vigotski busca tratar supostos estágios de desenvolvimento cultural apenas como diferentes entre si e não como inferiores ou superiores; entretanto, coerentemente com as concepções predominantes em seu tempo, ele na verdade concebe 0 pensamento racional e escolarizado como o modo mais avançado de funcionamento psicológico. Sendo assim, sua visão sobre essa questão poderia ser atualmente considerada evolucionista e eurocêntrica, e os termos homem primitivo e homem cultural, mantidos nesta tradução por fidelidade ao original, são bastante questionáveis. (N. de T.) 
resposta pelo caminho direto está impedida; em outras palavras, quando a situação apresenta exigências tais, que a resposta primitiva revela-se insatisfatória. Como regra geral, podemos considerar isso como operações culturais complexas da criança. A criança começa a recorrer a caminhos indiretos quando, pelo caminho direto, a resposta é dificultada, ou seja, quando as necessidades de adaptação que se colocam diante da criança excedem suas possibilidades, quando, por meio da resposta natural, ela não consegue dar conta da tarefa em questão.

A título de exemplo, apresentamos nosso experimento, que é uma modificação do experimento de Jean Piaget com a fala egocêntrica da criança ${ }^{2}$. Observamos a fala egocêntrica da criança aproximadamente na mesma situação em que Piaget, mas nos propusemos investigar de que fatores ela depende. Diferentemente do experimento de Piaget, dificultamos o comportamento da criança. Nós a observamos no momento de seu desenho livre, mas organizamos a atividade de modo que falte à criança determinado lápis de cor. Enquanto ela está entretida com o desenho, nós retiramos, imperceptivelmente, o modelo a partir do qual ela desenha; quando ela copia o desenho em um papel de seda, retiramos, imperceptivelmente, a tachinha e a folha se solta. Em suma, organizamos o comportamento da criança de modo que ela depare com uma série de dificuldades. Constatamos, nesses casos, que a fala egocêntrica imediatamente sobe para 96\%, enquanto seu coeficiente normal fica em torno de $47 \%$. Isso demonstra que a fala egocêntrica intensifica-se quando surgem dificuldades para a criança. Vamos supor que uma criança está desenhando e precisa de um lápis vermelho. Se o lápis estiver ali, surgirá a fala egocêntrica? Não. Ela precisa do lápis vermelho, pega-o e desenha. Agora vamos supor que a criança precise do lápis vermelho, mas ele não está lá; ela olha e o lápis não está ali. É aí que surge a fala egocêntrica, o raciocínio: "Sumiu o lápis vermelho, preciso arranjar

2- Quando utiliza o conceito de fala egocêntrica em Piaget, Vigotski refere-se à obra A linguagem e o pensamento da criança, de 1923. (N. de T.) um lápis vermelho", ou "A lebre vai ficar sem orelhas", ou "Vou ter que desenhar com o lápis cinza", ou "Se eu molhar o azul na água, ele vai ficar como vermelho", e assim faz a criança. Em outras palavras, quando não é possível dar conta da situação por meio de uma ação, surge em cena o raciocínio: como planejar o próprio comportamento ou como conseguir o objeto que lhe falta. Às vezes, a criança tenta dar-se conta do que está acontecendo. Esse caminho indireto aparece quando o caminho direto está impedido.

0 experimento nos convence de que a fala egocêntrica da criança é uma importante função do discurso interior, uma vez que ela planeja o comportamento. Sabemos até que ponto aquilo que vem à mente da pessoa influencia o que ela faz e em que medida isso é característico do comportamento humano, condiciona seus atos, sua atitude em relação ao meio circundante. As origens desse planejamento encontram-se na fala egocêntrica infantil.

0 pesquisador suíço Édouard Claparède demonstrou as leis que explicam a estrutura de tais operações indiretas; elas foram por ele denominadas leis da dificuldade de tomada de consciência $^{3}$. Claparède pesquisou como surge, na criança, a resposta ao semelhante e ao diferente e deparou com os seguintes fatos: a resposta ao semelhante surge antes da resposta ao diferente, enquanto a definição verbal do diferente surge antes da definição verbal do semelhante. Claparède explica isso da seguinte forma: com relação à semelhança, não há difıculdades para a criança, ela reage diretamente, não tem motivos para recorrer ao caminho indireto; com relação ao diferente, ela erra muito mais, realiza uma e outra ação, e, assim, revela-se como surge a operação indireta. Claparède formulou esta lei: procuramos compreender em

3 - Édouard Claparède (1873-1940), em A educação funcional (1931), apresenta um conjunto de grandes leis da conduta, entre as quais se encontra a lei da tomada de consciência aqui citada por Vigotski. Tal lei estabelece que o indivíduo comporta-se em relação a determinado objeto ou processo inicialmente de forma automática, inconsciente. Posteriormente, ele toma consciência desse objeto e pode comportar-se em relação a ele recorrendo a caminhos indiretos, a partir de uma escolha consciente e não levado por reações diretas, automáticas. (N. de T.) 
palavras ou traduzimos a operação do plano das ações para o plano verbal à medida que aprendemos a adaptarmo-nos, conforme deparamos com dificuldades em nosso comportamento.

E, realmente, não apenas os pesquisadores da fala egocêntrica, mas também os pesquisadores de operações mais complexas, demonstram que a estrutura dos caminhos indiretos surge quando a operação pelo caminho direto está impedida. Em outras palavras, a função básica e o objetivo fundamental da forma superior de adaptação consistem em fazer com que ela ocorra quando a adaptação pelo caminho direto fica difícil para a criança.

Há ainda um ponto extremamente importante, que pode ser assim formulado: o desenvolvimento das formas superiores de comportamento acontece sob pressão da necessidade; se a criança não tiver necessidade de pensar, ela nunca irá pensar. Se as dificuldades organizadas por nós obrigam a criança a corrigir seu comportamento, a pensar antes de agir, a tomar consciência em palavras, como diz Claparède, então acontece a situação mencionada. Mas, se organizamos o experimento de modo que a criança não depare com dificuldades, então a porcentagem de sua fala egocêntrica diminui imediatamente de $96 \%$ para $47 \%$, ou seja, cai quase pela metade.

Antes, os psicólogos estudavam o processo de desenvolvimento cultural da criança e o processo de sua educação de forma unilateral. Assim, todos se perguntavam quais dados naturais da psicologia da criança condicionam a possibilidade de seu desenvolvimento cultural, em quais funções naturais da criança deve apoiar-se o pedagogo para introduzi-la nessa ou naquela esfera da cultura. Estudavam, por exemplo, como o desenvolvimento da fala, ou a aprendizagem da aritmética, depende de funções naturais da criança, como ele é preparado no processo de crescimento natural da criança, mas não estudavam o contrário: como a assimilação da fala ou da aritmética transforma as funções naturais do aluno, como ela reconstrói todo o curso de seu pensamento natural, como rompe e afasta linhas e tendências antigas de seu desenvolvimento.

Agora, o educador começa a compreender que, ao entrar na cultura, a criança não apenas toma algo dela, adquire algo, incute em si algo de fora, mas também a própria cultura reelabora todo o comportamento natural da criança e refaz de modo novo todo o curso do desenvolvimento.

A distinção de dois planos de desenvolvimento no comportamento (o natural e o cultural) torna-se o ponto de partida para uma nova teoria da educação.

0 segundo ponto é ainda mais importante. Ele, pela primeira vez, introduz no campo da educação a concepção dialética do desenvolvimento da criança. Se antes, quando não se distinguiam os dois planos de desenvolvimento - o natural e o cultural -, era possível apresentar ingenuamente o desenvolvimento cultural da criança como continuação e consequência direta de seu desenvolvimento natural, agora tal compreensão resulta impossivel. Os antigos pesquisadores não viam um conflito profundo na transição, por exemplo, do balbucio às primeiras palavras ou da percepção das figuras numéricas ao sistema decimal. Eles consideravam que um era mais ou menos a continuação do outro. Novas pesquisas têm mostrado, e nisso está seu inestimável mérito, que, onde antes se via um caminho plano, na verdade há uma ruptura; onde parecia existir um movimento bem-sucedido por uma superfície plana, na realidade acontecem saltos. Simplificando, as novas pesquisas indicaram pontos de viragem no desenvolvimento, em que os antigos supunham haver um movimento em linha reta. Com isso, elas esclareceram os pontos nodais do desenvolvimento da criança mais importantes para a educação. Mas é natural que, juntamente com isso, desapareça também a antiga concepção sobre o próprio caráter da educação. Onde a antiga teoria podia falar em colaboração, a nova fala em luta. No primeiro caso, a teoria ensinava à criança a dar passos lentos e tranquilos; a nova deve ensiná-la a saltar. Essa 
mudança radical no ponto de vista educacional, que emerge como resultado da revisão dos problemas fundamentais do desenvolvimento cultural da criança, pode ser ilustrada em cada problema metodológico, em cada capítulo de nossa pesquisa.

A tarefa de cada teoria científica inclui a análise das relações existentes entre 0 meio e o organismo e dos seus principais tipos. Entretanto, essa posição expressa, de fato, a ideia de que o desenvolvimento da criança em cada época cultural coincide mais ou menos com pontos determinados da linha de seu desenvolvimento cultural. Assim, se examinarmos fenotipicamente o fenômeno, à primeira vista parece de fato que, em certo estágio de desenvolvimento do cérebro e de acúmulo de experiência, a criança adquire a fala humana; num estágio mais avançado, ela domina o sistema numérico; mais adiante, em condições favoráveis, entra no mundo da álgebra. Aqui é como se houvesse plena coincidência ou, mais provavelmente, concordância das linhas de desenvolvimento. Mas esse é um ponto de vista enganoso. Por trás dele esconde-se uma discrepância profunda, um conflito complexo, em que sempre se transforma o encontro com um novo estágio de desenvolvimento, pois, na verdade, a linha de desenvolvimento natural da criança, entregue à própria lógica, nunca passa para a linha do desenvolvimento cultural.

A transformação do material natural em uma forma histórica é sempre um processo não de simples mudança orgânica, mas de complexa mudança do próprio tipo de desenvolvimento. Assim, a principal conclusão que pode ser tirada da história do desenvolvimento cultural da criança, em relação à sua educação, é a seguinte: à educação cumpre sempre enfrentar uma subida onde antes se via um caminho plano; ela deve dar um salto onde até então parecia ser possível limitar-se a um passo. 0 primeiro mérito da nova pesquisa consiste exatamente em ter revelado um quadro complexo onde antes se via um simples. Mas esse ponto de vista produz uma verdadeira revolução nos princí- pios da educação quando nos aproximamos da educação da criança anormal.

Aqui o caso é essencialmente diferente daquele observado no campo da educação da criança normal. Todo o aparato da cultura humana (da forma exterior de comportamento) está adaptado à organização psicofísiológica normal da pessoa. Toda a nossa cultura é calculada para a pessoa dotada de certos órgãos - mão, olho, ouvido - e de certas funções cerebrais. Todos os nossos instrumentos, toda a técnica, todos os signos e símbolos são calculados para um tipo normal de pessoa. E daqui surge aquela ilusão de convergência, de passagem natural das formas naturais às culturais, que, de fato, não é possível pela própria natureza das coisas e a qual tentamos revelar em seu verdadeiro conteúdo.

Quando surge diante de nós uma criança que se afasta do tipo humano normal, com o agravante de uma deficiência na organização psicofisiológica, imediatamente, mesmo aos olhos de um observador leigo, a convergência dá lugar a uma profunda divergência, uma discrepância, uma disparidade entre as linhas natural e cultural do desenvolvimento da criança. Por si só, entregue a seu desenvolvimento natural, a criança surda-muda nunca aprenderá a falar, a cega nunca dominará a escrita. Aqui a educação surge em auxílio, criando técnicas artificiais, culturais, um sistema especial de signos ou símbolos culturais adaptados às peculiaridades da organização psicofısiológica da criança anormal.

Assim, no caso dos cegos, a escrita visual é substituída pela tátil - o sistema Braille permite compor todo o alfabeto por meio de diferentes combinações de pontos em relevo, permite ler tocando esses pontos na página, e escrever perfurando o papel e marcando nele pontos em relevo. Exatamente do mesmo modo, no caso dos surdos-mudos, a dactilologia (ou alfabeto manual) permite substituir por signos visuais, por diversas posições das mãos, os signos sonoros do nosso alfabeto e compor no ar uma escrita especial, que a criança surda-muda lê com os olhos. 
A educação vai ainda mais longe e ensina ao surdo-mudo a língua falada, uma vez que seu aparelho fonador geralmente não está prejudicado. Essa criança, surda de nascença, só se torna muda por estar privada de percepção auditiva. A educação ensina o surdo a compreender a língua falada pela leitura dos lábios do falante, ou seja, substituindo os sons da fala por imagens visuais, movimentos da boca e dos lábios. 0 surdo-mudo aprende a falar utilizando, para isso, o tato, a imitação de sinais e as sensações cinestésicas.

Esses caminhos alternativos especialmente construídos para o desenvolvimento cultural da criança cega e da surda-muda, a língua escrita e falada especialmente criada para elas são extremamente importantes na história do desenvolvimento cultural em dois aspectos. Os cegos e os surdos-mudos são como um experimento natural que demonstra que o desenvolvimento cultural do comportamento não se relaciona, necessariamente, com essa ou aquela função orgânica. A fala não está obrigatoriamente ligada ao aparelho fonador; ela pode ser realizada em outro sistema de signos, assim como a escrita pode ser transferida do caminho visual para o tátil.

Os casos de desenvolvimento anômalo permitem observar, com máxima clareza, a divergência entre o desenvolvimento cultural e o natural, a qual, em essência, ocorre também na criança normal, mas aqui emerge com máxima nitidez justamente porque, entre os surdos-mudos e os cegos, nota-se uma impressionante discrepância entre as formas culturais de comportamento, destinadas à organização psicofısiológica normal da pessoa, e o comportamento da criança acometida por essa ou aquela deficiência. Porém, mais importante, as formas culturais de comportamento são o único caminho para a educação da criança anormal. Elas consistem na criação de caminhos indiretos de desenvolvimento onde este resulta impossível por caminhos diretos. A língua escrita para os cegos e a escrita no ar para os surdos-mudos são tais caminhos psicofisiológicos alternativos de desenvolvimento cultural.
Nós nos acostumamos com a ideia de que o homem lê com os olhos e fala com a boca, e somente o grande experimento cultural que mostrou ser possivel ler com os dedos e falar com as mãos revela-nos toda a convencionalidade e a mobilidade das formas culturais de comportamento. Psicologicamente, essas formas de educação conseguem superar o mais importante, ou seja, a educação consegue incutir na criança surda-muda e na cega a fala e a escrita no sentido próprio dessas palavras.

0 importante é que a criança cega lê, assim como nós lemos, mas essa função cultural é garantida por um aparato psicofisiológico completamente diferente do nosso. E, para a criança surda-muda, o mais importante, do ponto de vista do desenvolvimento cultural, é que a fala humana é garantida por um aparato psicofisiológico completamente diferente.

Dessa forma, a primeira lição que esses exemplos nos ensinam é a independência das formas culturais de comportamento em relação a esse ou aquele aparato psicofısiológico. A segunda lição, particularmente evidente no exemplo das crianças surdas-mudas, refere-se ao desenvolvimento espontâneo das formas culturais de comportamento. As crianças surdas-mudas, por si mesmas, desenvolvem uma língua mímica complexa, uma fala singular. É criada uma forma particular de fala não para surdos-mudos, mas construída pelos próprios surdos-mudos. É criada uma língua original, que se distingue de todas as línguas humanas contemporâneas mais profundamente do que estas entre si, pois ela retorna à mais antiga protolíngua humana, à língua dos gestos ou até mesmo só das mãos.

Por si só, mesmo privada de qualquer instrução, a criança ingressa no caminho do desenvolvimento cultural; em outras palavras, é no desenvolvimento psicológico natural da criança e no seu meio circundante, na necessidade de comunicação com esse meio, que se encontram todos os dados necessários para que se realize uma espécie de autoignição do desenvolvimento cultural, uma passagem 
espontânea da criança do desenvolvimento natural ao cultural.

Esses dois aspectos, tomados em conjunto, levam-nos a uma reavaliação radical do olhar contemporâneo sobre a educação da criança anormal. 0 olhar tradicional partia da ideia de que o defeito significa menos, falha, deficiência, limita e estreita o desenvolvimento da criança, o qual era caracterizado, antes de mais nada, pelo ângulo da perda dessa ou daquela função. Toda a psicologia da criança anormal foi construída, em geral, pelo método da subtração das funções perdidas em relação à psicologia da criança normal.

Para substituir essa compreensão, surge outra, que examina a dinâmica do desenvolvimento da criança com deficiência partindo da posição fundamental de que o defeito exerce uma dupla influência em seu desenvolvimento. Por um lado, ele é uma deficiência e atua diretamente como tal, produzindo falhas, obstáculos, dificuldades na adaptação da criança. Por outro lado, exatamente porque o defeito produz obstáculos e dificuldades no desenvolvimento e rompe o equilíbrio normal, ele serve de estímulo ao desenvolvimento de caminhos alternativos de adaptação, indiretos, os quais substituem ou superpõem funções que buscam compensar a deficiência e conduzir todo o sistema de equilíbrio rompido a uma nova ordem.

Dessa forma, o novo ponto de vista prescreve que se considere não apenas as características negativas da criança, não só suas faltas, mas também um retrato positivo de sua personalidade, o qual apresenta, antes de mais nada, um quadro dos complexos caminhos indiretos do desenvolvimento. 0 desenvolvimento das funções psíquicas superiores é possível somente pelos caminhos do desenvolvi- mento cultural, seja ele pela linha do domínio dos meios externos da cultura (fala, escrita, aritmética), ou pela linha do aperfeiçoamento interno das próprias funções psíquicas (elaboração da atenção voluntária, da memória lógica, do pensamento abstrato, da formação de conceitos, do livre-arbítrio e assim por diante). As pesquisas mostram que a criança anormal, em geral, tem atrasos justamente nesse aspecto. Tal desenvolvimento não depende da deficiência orgânica.

Eis por que a história do desenvolvimento cultural da criança permite propor a seguinte tese: o desenvolvimento cultural é a principal esfera em que é possível compensar a deficiência. Onde não é possível avançar no desenvolvimento orgânico, abre-se um caminho sem limites para o desenvolvimento cultural.

Ao falar sobre talento, detemo-nos especialmente no modo como a cultura nivela as diferenças de talento e como o desenvolvimento cultural apaga ou, mais precisamente, converte em histórica a superação natural do desenvolvimento orgânico incompleto.

Resta-nos apenas acrescentar que, em relação ao desenvolvimento cultural dos meios internos de comportamento (atenção voluntária e pensamento abstrato), deve ser criada a mesma técnica de caminhos alternativos que existe em relação ao desenvolvimento dos meios externos do comportamento cultural. Para a criança intelectualmente atrasada, deve ser criado, em relação ao desenvolvimento de suas funções superiores de atenção e pensamento, algo que lembre o sistema Braille para a criança cega ou a dactilologia para a muda, isto é, um sistema de caminhos indiretos de desenvolvimento cultural, quando os caminhos diretos estão impedidos devido ao defeito. 